\title{
Relationship between Primary- and Secondary-dendrite Arm Spacing of C-Mn Steel Uni-directionally Solidified in Steady State
}

\author{
Masana IMAGUMBAI
}

Kimitsu R \& D Laboratory, Technical Development Bureau, Nippon Steel Corporation, Kimitsu, Kimitsu, Chiba, 299-11 Japan.

(Received on May 18, 1994; accepted in final form on September 16, 1994)

\begin{abstract}
The relationship between primary dendrite arm spacing and secondary one was investigated in experiment, and was found that the latter is roughly one half of the former. Theoretically, the primary arm spacing is interpreted by thermodynamic perturbations ahead of the primary tip. On the contrary growth mechanism of secondary arm is ascribed to Ostwald-ripening and/or sintering/coalescence mechanism. The experimental result is analysed by the mechanisms, and is shown the 'one half relationship' is a good approximation.
\end{abstract}

KEY WORDS: dendrite arm spacing; dendrite morphology; thermodynamic perturbation; Ostwald-ripening.

\section{Introduction}

In the previous publication ${ }^{1)}$ by the author, dendrite arm spacings of $\mathrm{C}-\mathrm{Mn}$-steel in steady state unidirectional solidification are investigated. The physical variables characterizing solidification conditions, e.g., growth rate of primary dendrite tip: $R$ and temperature gradient around solid/liquid zone: $G$ are the most significant ones, and the results in the publication ${ }^{1)}$ are correlated to the following relationships;

$$
\begin{aligned}
& \lambda_{1}[\mu \mathrm{m}]=1750 R^{-0.14} G^{-0.50} \quad\left[R: \mu \mathrm{m} / \mathrm{s}, G:{ }^{\circ} \mathrm{C} / \mathrm{mm}\right] \\
& \lambda_{2}^{f} \quad \sim 0.5 \lambda_{1}
\end{aligned}
$$

where $\lambda_{1}$ is primary arm spacing and $\lambda_{2}^{f}$ is secondary arm spacing at completely solidified zone. The experimental results are examined by the theories based mainly on Kurz and Fisher, ${ }^{2,3)}$ who evolved it from a thermodynamic consideration which is first proposed by Mullins and Sekerka, ${ }^{4)}$ and is developed by Langer and Müller-Krumbhaar ${ }^{5-8)}$ into perturbation around primary dendrite tips. For the secondary dendrite growth, Ostwald-ripening mechanism ${ }^{9)}$ and/or sintering/coalescence behaviour ${ }^{10)}$ are applied.

\section{Theoretical Bases}

Mullins et al ${ }^{4)}$ explained the statistical fluctuation of solute concentration and temperature around a solid/ liquid interface which moves at a constant velocity $R$, applying three equations of continuity in terms of a co-ordinate whose origin is set at the operating point moving in the $z$-direction at the same velocity $R$;

$$
\left.\begin{array}{l}
\nabla^{2} C+(R / D) \partial C / \partial z=0 \\
\nabla^{2} T+\left(R / D_{t h}\right) \partial T / \partial z=0 \\
\nabla^{2} T^{\prime}+\left(R / D_{t h}^{\prime}\right) \partial T^{\prime} / \partial z=0
\end{array}\right\}
$$

where $C, T$ and $T^{\prime}$ represent solute concentration in liquid, temperature in liquid and temperature in solid, respectively. Each solution for $C, T$ and $T^{\prime}$ is analysed with infinitesimal sinusoidal Fourier components which simulate sinusoidal ripple of the tip interface expressed as

$$
z=\delta(t) \sin \omega x
$$

where $\delta(t)$ is amplitude of perturbation, $\omega$ corresponds to the ripple frequency, and $x$ is radial co-ordinate. Mullins et al. put the following four conditions;

(i) perturbed $C, T$ and $T^{\prime}$ around the tip-interface should agree with the unperturbed field at several wavelengths from the interface,

(ii) at the tip interface, temperature: $T_{I}$ and solute concentration: $C_{I}$ at the operating tip and temperature of supercooled melt ahead of the tip: $T_{N}$ are related to the solute concentration gradient $M$, as $T_{I}=M C_{I}+T_{N}$, and

(iii) the classical law for critical nucleation radius at the tip: $T_{N}=T_{E}+2 \sigma T_{E} / A r$ is applied, where $T_{E}$ is equilibrium melting temperature, $\sigma$ is the specific solid/liquid interface free energy, and $A$ is latent heat of melt per unit volume,

(iv) at any point of tip interface, the velocity $R(x)$ must satisfies the following equation of solutal diffusion,

$$
\begin{aligned}
R(x) & =\left\{K_{S}\left(\partial T^{\prime} / \partial z\right)_{I}-K_{L}(\partial T / \partial z)_{I}\right\} / \Lambda \\
& =D(\partial T / \partial z)_{I} /\left\{C_{I}(k-1)\right\}
\end{aligned}
$$

and obtained the relative differential rate of the amplitude;

$$
\begin{aligned}
\dot{\delta} / \delta= & R \omega\left\{-2 T_{E} \Gamma^{\prime} \omega^{2}\left[\omega^{*}-(R / D) p\right]\right. \\
- & \left.\left(g^{\prime}+g\right)\left[\omega^{*}-(R / D) p\right]+2 M G_{C}\left[\omega^{*}-(R / D)\right]\right\} / \\
& \left\{\left(g^{\prime}-g\right)\left[\omega^{*}-(R / D) p\right]+2 \omega M G_{C}\right\}
\end{aligned}
$$

which signifies stability/unstability of the ripple, or perturbation. Very clearly

$$
\dot{\delta} / \delta=0
$$


means that the perturbation ahead of the tip interface continues to propagate with a ripple shape unchanged, i.e., perturbed tip proceeds forward with stable morphology.

Langer et al. ${ }^{5-8)}$ applied the central result of Mullins et al., ${ }^{4)}$

$$
\lambda_{s}=2 \pi\left(2 D d_{0} / R\right)^{1 / 2}
$$

to side-branching behavior around primary dendrite tip, using a parabolic co-ordinate (cartesian co-ordinate), where $\lambda_{s}$ is minimum wavelength of perturbation, $d_{0}$ is capillarity length of primary arm-buds, or height of ripple at the tip.

According to their calculation, ${ }^{6-8)}$ displacement of interface from unperturbed paraboloid, or perturbation, is given with $F(\xi, t)$ as shown in Fig. 1, where $F(\xi, t)$ is expressed as $\exp [\Omega(t-\xi)] J_{0}(2 \Omega \sqrt{\xi})$ with $\xi$ representing distance from primary tip center in parabolic co-ordinates, $\Omega$ : supersaturation and $J_{0}$ : ordinary Bessel function, and the relationship between tip radius: $r$ and dimensionless growth rate, or Péclet number: $R d_{0} / 2 D$ is given as shown in Fig. 2. From their computer calculation, the dimensionless parameter: $\left(2 D / R d_{0}\right) /\left(r / d_{0}\right)^{2}$ was given as $\mathrm{Eq}$. (8),

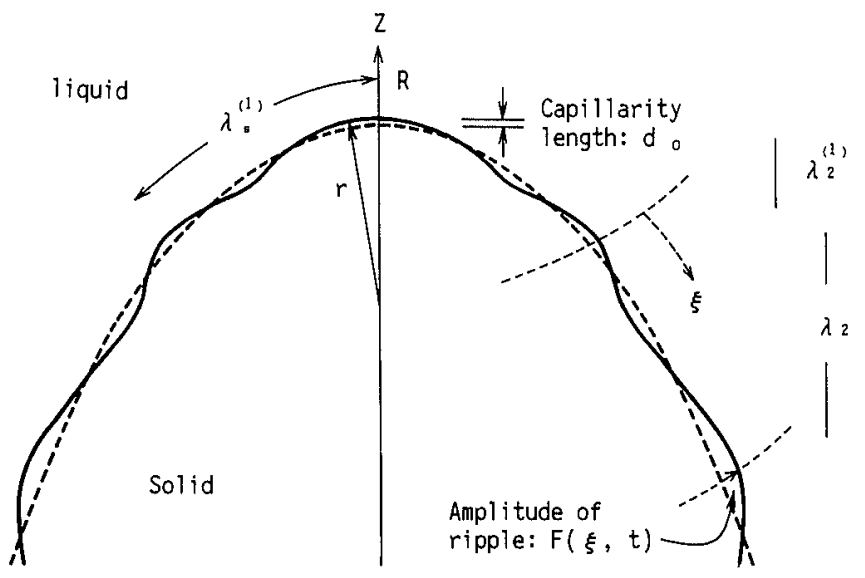

Fig. 1. Perturbation ahead of primary dendrite tip illustrating ripple of thermodynamic fluctuation of solute-concentration/temperature, after Langer et al..$^{5-8)}$

$$
\left(2 D / R d_{0}\right) /\left(r / d_{0}\right)^{2}=2 D d_{0} / R r^{2} \sim 0.025
$$

at the dynamically stable operating point of a dendrite surface where the secondary capillarity length $d_{0}=$ $F(\xi, t)$ is calculated for a supercooling of $0.05(\Lambda / \mathrm{Cp})$ for which experimental data was available. The dimensionless parameter originates from a stability criterion which is ordinarily referred to Ivantsov isothermal mode, etc., expressed as $R r^{2}=$ constant. Equation (8) is inserted into Eq. (7), then Eq. (9) is obtained.

$$
\lambda_{S} \sim r
$$

Kurz et al. ${ }^{2,3)}$ simplified Eq. (5) with the following delicate approximations, (i) localized tip is deemed as flat plane, (ii) $\Lambda \sim 0$, (iii) $D_{t h} \sim D_{t h}^{\prime}$, (iv) $k \sim 0$, and introduced

$$
\lambda_{S}=2 \pi\left[\Gamma /\left(M G_{C}-G\right)\right]^{1 / 2}
$$

from which a relationship between $R$ and $r$ is obtained as Eq. (11). According to Kurz et al., Eq. (11) is further simplified to Eq. (12), provided $R$ is large enough comparing to dendrite/cellular criterion; $R_{t r}=G D / \Delta T_{0} k$,

$$
\begin{array}{r}
R=2 D\left(G r^{2}+4 \pi^{2} \Gamma\right) /\left(r^{3} p G-2 r^{2} p C_{0} M+4 \pi^{2} \Gamma r p\right) \\
R \sim 4 \pi^{2} D \Gamma / r^{2} \Delta T_{0} k \ldots \ldots \ldots \ldots \ldots \ldots \ldots \ldots \ldots \ldots \ldots
\end{array}
$$

Kurz et al. further postulated an axial-symmetric ellipsoid shape for an overall primary dendrite arm, and devised a relationship between $\lambda_{1}$ and solidification variables, as follows,

$$
\lambda_{1}=4.3\left(\Delta T_{m}\right)^{1 / 2}\left(D \Gamma / \Delta T_{0} k\right)^{1 / 4} R^{-1 / 4} G^{-1 / 2}
$$

\section{Experiments}

Sample steels containing approximately $0.6 \% \mathrm{C}-$ $0.6 \% \mathrm{Mn}$ in mass $\%$ were solidified under steady state uni-directional solidification conditions. Steel a; $0.62 \% \mathrm{C}$ $0.12 \% \mathrm{Si}-0.58 \% \mathrm{Mn}-0.006 \% \mathrm{P}-0.073 \% \mathrm{~S}-0.049 \% \mathrm{Al}-$ $0.0011 \% \mathrm{O}$, Steel b; $0.52 \% \mathrm{C}-0.10 \% \mathrm{Si}-0.56 \% \mathrm{Mn}-$ $0.003 \% \mathrm{P}-0.046 \% \mathrm{~S}-0.037 \% \mathrm{Al}-0.0011 \% \mathrm{O}$. The solidification variables in the experiments ranged for $R$, from 4.1 to $56 \mu \mathrm{m} / \mathrm{s}$, and for $G$, from 1.8 to $16^{\circ} \mathrm{C} / \mathrm{mm}$. During the sample was solidifying at the aimed steady state

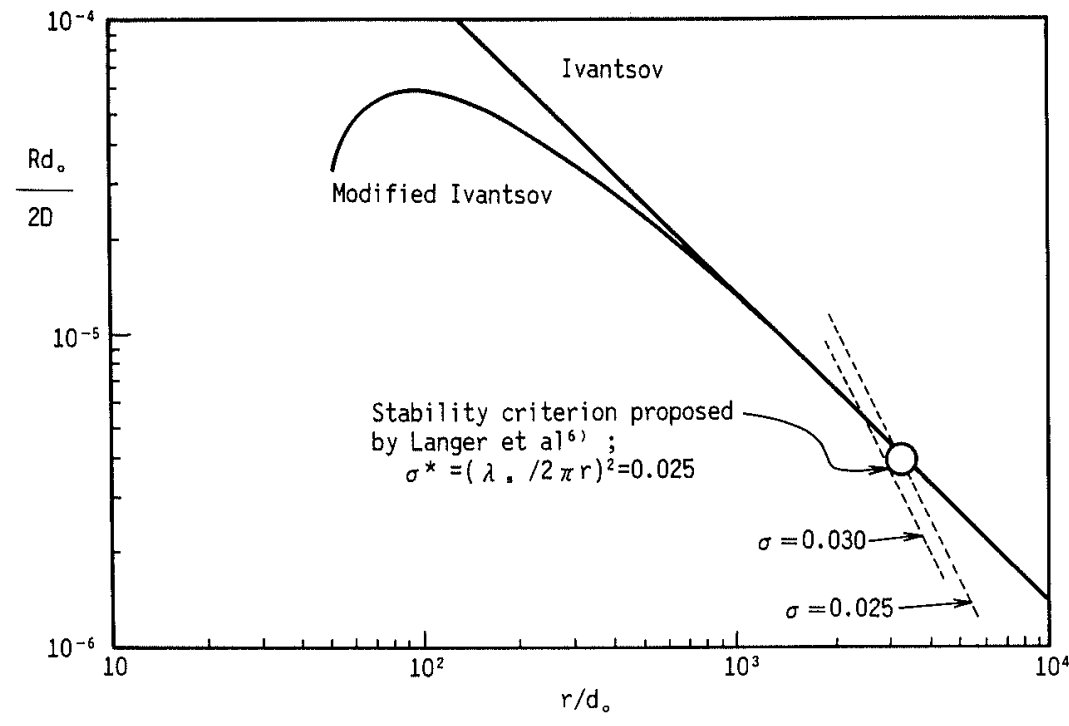

Fig. 2.

Dimension-less growth rate, or Péclet number: $R d_{0} /$ $2 D$ and dimension-less tip radius: $r / d_{0}$, after Langer et al. $^{5-8)}$ 
conditions, it was quenched, and dendrite arm spacings of primary arms: $\lambda_{1}$ and secondary ones: $\lambda_{2}$ were measured around the solid/liquid zone. Details of the experiments were explained in the previous publication. ${ }^{1)}$

\section{Analysis}

\subsection{Primary Arm Spacing}

All the experimental data, the physical data and solidification variables applied are listed in Table 1. $\lambda_{1}$-values are calculated by Eq. (13) and Eq. (1) and are shown in Table 2. The correlation between experiments and theoretical calculations is good as shown in Table
2. Also in Fig. 3, a calculation result of Eq. (11) is shown, taking a typical solidification conditions; $G=2^{\circ} \mathrm{C} / \mathrm{mm}$. It is understood Eq. (11) gives a good evaluation of $\lambda_{1}$ for wide range of $R$-value, although the exponent of $R$ in the experiment was -0.14 as mentioned before. ${ }^{1)}$ The exponent of $G$ in the experiment coinsides with the theory. This means the perturbation ahead of primary tip in the experiment can be explained with the theories by Mullins et al., i.e., Eqs. (6) and (7), Langer et al., i.e., Eqs. (8) and (9), and finally theoretical approximations by Kurz et al., i.e., Eqs. (10)-(12). Only the discrepancy about $R$-exponent remains unsolved. For further theoretical approach it must be necessary to continue additional

Table 1. Observed data of the present study ${ }^{1)}$ and some physical values used in the present discussion.

\begin{tabular}{|c|c|c|c|c|c|c|c|}
\hline $\begin{array}{l}\text { Test No. } \\
\text { Steel } \\
{[\text { mass } \% C]}\end{array}$ & $\begin{array}{c}\$ 9 \\
a \\
0.62\end{array}$ & $\begin{array}{c}\# 5 \\
a \\
0.62\end{array}$ & $\begin{array}{c}\# 3 \\
a \\
0.62\end{array}$ & $\begin{array}{c}\# 11 \\
a \\
0.62\end{array}$ & $\begin{array}{c}\# 12 \\
b \\
0.52\end{array}$ & $\begin{array}{c}\# 13 \\
b \\
0.52\end{array}$ & $\begin{array}{c}\# 17 \\
b \\
0.52\end{array}$ \\
\hline$T_{L} \quad\left[{ }^{\circ} \mathrm{C}\right]$ & 1490 & 1490 & 1490 & 1490 & 1496 & 1496 & 1496 \\
\hline$T_{S} \quad\left[{ }^{\circ} \mathrm{C}\right]$ & 1423 & 1423 & 1423 & 1423 & 1438 & 1438 & 1438 \\
\hline$T_{e} \quad\left[{ }^{\circ} \mathrm{C}\right]$ & 1320 & $<1320$ & $<1320$ & $<1320$ & 1350 & 1350 & 1350 \\
\hline$\Delta T_{0} \quad\left[{ }^{\circ} \mathrm{C}\right]$ & 67 & 67 & 67 & 67 & 58 & 58 & 58 \\
\hline$D^{15)} \quad\left[\mathrm{cm}^{2} / \mathrm{s}\right]$ & $2.74 \times 10^{-5}$ & $2.74 \times 10^{-5}$ & $2.74 \times 10^{-5}$ & $2.74 \times 10^{-5}$ & $2.79 \times 10^{-5}$ & $2.79 \times 10^{-5}$ & $2.79 \times 10^{-5}$ \\
\hline$\Gamma^{16)}\left[{ }^{\circ} \mathrm{Ccm}\right]$ & $1 \times 10^{-5}$ & $1 \times 10^{-5}$ & $1 \times 10^{-5}$ & $1 \times 10^{-5}$ & $1 \times 10^{-5}$ & $1 \times 10^{-5}$ & $1 \times 10^{-5}$ \\
\hline$k$ & 0.34 & 0.34 & 0.34 & 0.34 & 0.34 & 0.34 & 0.34 \\
\hline$[\mu \mathrm{m} / \mathrm{s}]$ & 28.7 & 56.2 & 28.8 & 21.8 & 5.28 & 4.97 & 4.12 \\
\hline$G \quad\left[{ }^{\circ} \mathrm{C} / \mathrm{mm}\right]$ & 1.99 & 1.81 & 4.81 & 16.3 & 2.04 & 4.83 & 10.9 \\
\hline$[\mu \mathrm{m}]$ & 862 & 717 & 474 & 272 & 910 & 626 & 462 \\
\hline$\lambda_{2}^{f} \quad[\mu \mathrm{m}]$ & 316 & 301 & 257 & 172 & 434 & 362 & 228 \\
\hline
\end{tabular}

Table 2. Comparison between observed $\lambda_{1}$ and calculated $\lambda_{1}$ with Eq. (13).

\begin{tabular}{|c|c|c|c|c|c|c|c|}
\hline $\begin{array}{l}\text { Test No. } \\
\text { Steel }\end{array}$ & $\begin{array}{c}\# 9 \\
a\end{array}$ & $\begin{array}{c}\# 5 \\
\mathrm{a}\end{array}$ & $\begin{array}{c}\# 3 \\
\mathrm{a}\end{array}$ & $\begin{array}{c}\# 11 \\
\mathrm{a}\end{array}$ & $\begin{array}{c}\# 12 \\
b\end{array}$ & $\begin{array}{c}\# 13 \\
\mathrm{~b}\end{array}$ & $\begin{array}{c}\# 17 \\
b\end{array}$ \\
\hline Obs. $\lambda_{1}[\mu \mathrm{m}]$ & 862 & 717 & 474 & 272 & 910 & 626 & 462 \\
\hline Cal. $\lambda_{1}[\mu \mathrm{m}]$ by Eq. (13) & 787 & 698 & 506 & 295 & 1140 & 754 & 526 \\
\hline Cal. $\lambda_{1}[\mu \mathrm{m}]$ by Eq. (1) & 775 & 740 & 499 & 282 & 970 & 636 & 435 \\
\hline
\end{tabular}

Eq. (13) $\lambda_{1}=4.3\left(\Delta T_{m}\right)^{1 / 2}\left(D \Gamma / \Delta T_{0} k\right)^{1 / 4} R^{-1 / 4} G^{-1 / 2}$

[for steel a] $\lambda_{1}[\mu \mathrm{m}]=2570 R^{-0.25} G^{-0.50}\left[R: \mu \mathrm{m} / \mathrm{s}, G:{ }^{\circ} \mathrm{C} / \mathrm{mm}\right]$

[for steel b] $\lambda_{1}[\mu \mathrm{m}]=2470 R^{-0.25} G^{-0.50}\left[R: \mu \mathrm{m} / \mathrm{s}, G:{ }^{\circ} \mathrm{C} / \mathrm{mm}\right]$

Eq. (1) $\lambda_{1} \quad[\mu \mathrm{m}]=1750 R^{-0.14} G^{-0.50}\left[R: \mu \mathrm{m} / \mathrm{s}, G:{ }^{\circ} \mathrm{C} / \mathrm{mm}\right]$

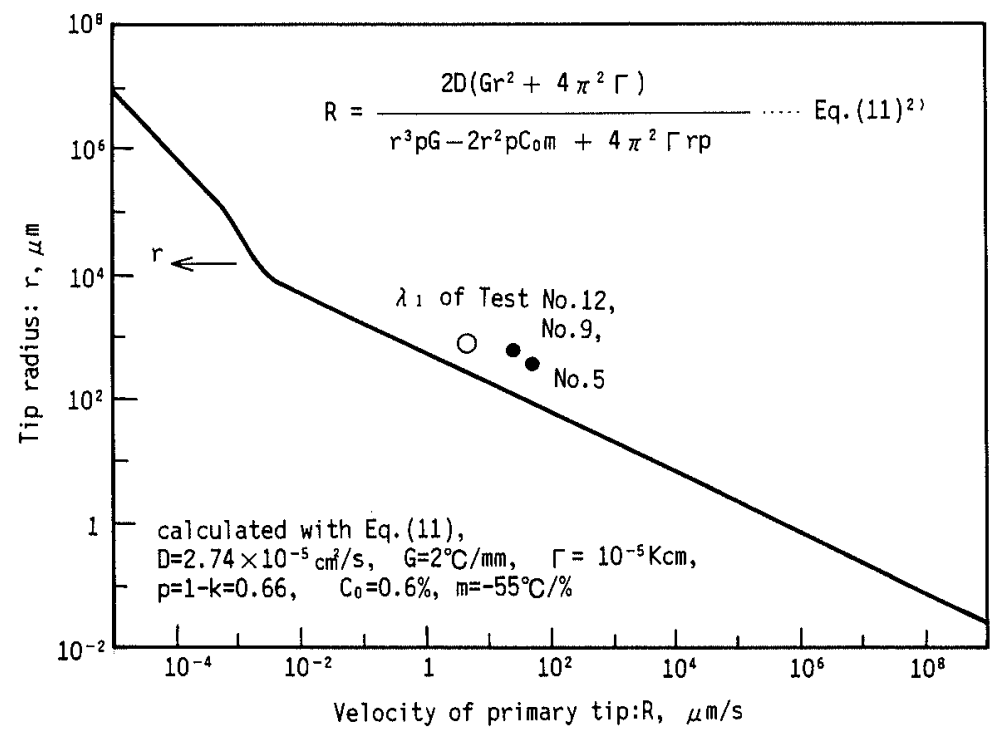

Fig. 3.

Relationship between velocity of primary dendrite tip: $R$ and tip radius: $r$ for $0.6 \% \mathrm{C}-0.6 \% \mathrm{Mn}$-steel, temperature gradient along solid/liquid: $G \sim 2^{\circ} \mathrm{C} / \mathrm{s}$. Solid circle: Steel a, open circle: Steel b in Table 1.

c.f., Open/solid circles indicate each calculated $\lambda_{1}$-value. 
observations on the actual shape of primary dendrite arm, although the present work involves no additional experiment about it.

\subsection{Secondary Dendrite Arm Spacing}

The incipient state of nucleation of secondary arms is obviously interpreted by the idea proposed by Langer and Müller-Krumbhaar as explained above. Then the growth, or exactly, roughening of minute secondary arms, is thought to be explained by Ostwald-ripening mechanism ${ }^{9)}$ and sintering/coalescence. ${ }^{10)}$ The result of the present author ${ }^{1)}$ as well as other published data ${ }^{11-13)}$ shows secondary arm spacing along solid/liquid zone: $\lambda_{2}$ depends on the time duration after primary tips intrude into the concerned location, $\tau$, as expressed with Eq. (14). Dann et al. ${ }^{14)}$ thought that Ostwald-ripening mechanism prevails in relatively

$$
\lambda_{2}=(\text { constant }) \cdot \tau^{m}
$$

early stage of secondary arm roughening, where the exponent $m$ falls on around 0.25 , on the contrary the later stage is explained by sintering/coalescence, where $m \sim 0.4$. On the other hand, many reports give the time-exponent $m$ of $\lambda_{2}$ as $m \sim 1 / 3$. To give an answer to the question whether $m$ is constant, e.g., $1 / 3$, or it changes along solid/liquid zone, further experiment is required. In the following discussion, $m=1 / 3$ is used.The data of the present author fluctuate around these figures as shown in another publication (refer to Fig. 3 in the publication ${ }^{1)}$ ). The transition of the kinetics is not necessarily clear.

Based on the Langers' theory, let the roughening mechanism be brought in effect at a location behind the primary tip by a distance of the radius of primary tip along the curvature, and at this location the wave length of perturbation is $\lambda_{S}$, which corresponds to $\lambda_{2}$ there, as shown in Fig. 1. Here the primary axial-distance between the tip-top and the starting point of roughening is taken as $c a$. (1/8) $r$ as shown in Fig. 1, where $r$ is primary tip radius and is regarded $\sim \lambda_{S}$, then Eq. (14) becomes.Eq. (15).

$$
\lambda_{2}=\lambda_{S}^{1-m}(8 R)^{m} \cdot \tau^{m}
$$

Using Kurz's calculation result of Eq. (12), $r\left(\sim \lambda_{S}\right)=$ $2 \pi\left(D \Gamma / R \Delta T_{0} k\right)^{1 / 2}$ is obtained, then Eq. (15) is expressed as

$$
\lambda_{2}=(2 \pi)^{1-m}\left(D \Gamma / R \Delta T_{0} k\right)^{(1-m) / 2}(8 R)^{m} \cdot \tau^{m}
$$

Putting $m=1 / 3$ as reported in the publications elsewhere, the secondary arm spacing: $\lambda_{2}^{e}$ at $\tau=\Theta_{f}=\Delta T_{0} / R G$ is calculated, and Eq. (17) is obtained.

$$
\lambda_{2}^{e}=6.8(D \Gamma / R G k)^{1 / 3}
$$

The calculated $\lambda_{2}^{e}$ by Eq. (17) evaluates the experimental data of secondary arm spacing at $T_{S}$ with satisfactory coincidence as shown in Table 3.

Obviously $\lambda_{2}^{e}$ is not the final secondary arm spacing: $\lambda_{2}^{f}$ which is the spacing at locations of fully solidified zone. There is no method calculating $\lambda_{2}^{f}$ from any of the above mentioned theoretical approachs, since the inter-dendritic enriched zone becomes an independent system from the thermodynamic point of view. The ratio: $\lambda_{2}^{e} / \lambda_{2}^{f}$, where $\lambda_{2}^{e}$ is secondary arm spacing at $T_{S}$ calculated by Eq. (17) and $\lambda_{2}^{f}$ is observed at quenched specimen, is obtained and shown in Table 4. The ratio $\lambda_{2}^{e} / \lambda_{2}^{f}$ ranges $0.47-0.52$ for steel $a$, and $0.61-0.78$ for steel $b$. That means the final secondary arm spacing approximately doubles the theoretical value of $\lambda_{2}^{e}$.

\subsection{Ratio of $\lambda_{2}^{f} / \lambda_{1}$}

Using the theoretical values for $\lambda_{1}$ by Eq. (13) and $\lambda_{2}^{e}$ by Eq. (17), ratio of $\lambda_{2}^{e} / \lambda_{1}$ is given by Eq. (18). The data of experiments are calculated with the Eq. (18) and listed

$$
\lambda_{2}^{e} / \lambda_{1}=1.6\left[\left(\Delta T_{0}\right)^{1 / 4} /\left(\Delta T_{m}\right)^{1 / 2}\right](D \Gamma / k)^{1 / 12} R^{-1 / 12} G^{1 / 6}
$$

in Table 4. In Table 4 the semi-theoretical results of $\lambda_{2}^{e} / \lambda_{2}^{f}$ are calculated, and are listed together. From the results

\begin{tabular}{|c|c|c|c|c|c|c|c|}
\hline $\begin{array}{l}\text { Test No. } \\
\text { Steel }\end{array}$ & $\begin{array}{l}\# 9 \\
\mathrm{a}\end{array}$ & $\begin{array}{l}\# 5 \\
\mathrm{a}\end{array}$ & $\begin{array}{c}\# 3 \\
\mathrm{a}\end{array}$ & $\begin{array}{c}\# 11 \\
\mathrm{a}\end{array}$ & $\begin{array}{c}\# 12 \\
b\end{array}$ & $\begin{array}{c}\# 13 \\
b\end{array}$ & $\begin{array}{c}\# 17 \\
b\end{array}$ \\
\hline$\lambda_{2}\left(T_{S}\right)[\mu \mathrm{m}]$ & 175 & 175 & 128 & 73 & 284 & 210 & 140 \\
\hline Cal. $\lambda_{2}^{e}[\mu \mathrm{m}]$ by Eq. (17) & 164 & 135 & 122 & 89 & 288 & 220 & 179 \\
\hline
\end{tabular}
in Table 4, it is thought the one half relationship: Eq. (2),

$$
\lambda_{2}^{f} \sim 0.5 \lambda_{1}
$$

Table 3. Comparison of observed $\lambda_{2}\left(T_{S}\right)$ with calculated $\lambda_{2}^{e}$ with Eq. (17).

Eq. (17) $\lambda_{2}^{e}=6.8(D \Gamma / R G k)^{1 / 3}$

[for steel a] $\lambda_{2}^{e}[\mu \mathrm{m}]=63.3(R G)^{-1 / 3}\left[R: \mathrm{cm} / \mathrm{s}, G:{ }^{\circ} \mathrm{C} / \mathrm{cm}\right]$

[for steel b] $\lambda_{2}^{e}[\mu \mathrm{m}]=63.6(R G)^{-1 / 3}\left[R: \mathrm{cm} / \mathrm{s}, G:{ }^{\circ} \mathrm{C} / \mathrm{cm}\right]$

Table 4. $\lambda_{2}^{e} / \lambda_{2}^{f}$ and calculated $\lambda_{2}^{e} / \lambda_{1}$ by Eq. (18).

\begin{tabular}{cccccccc}
\hline $\begin{array}{c}\text { Test No. } \\
\text { Steel }\end{array}$ & $\begin{array}{c}\# 9 \\
\mathrm{a}\end{array}$ & $\begin{array}{c}\# 5 \\
\mathrm{a}\end{array}$ & $\begin{array}{c}\# 3 \\
\mathrm{a}\end{array}$ & $\begin{array}{c}\# 11 \\
\mathrm{a}\end{array}$ & $\begin{array}{c}\# 12 \\
\mathrm{~b}\end{array}$ & $\begin{array}{c}\# 13 \\
\mathrm{~b}\end{array}$ & $\begin{array}{c}\# 17 \\
\mathrm{~b}\end{array}$ \\
\hline (1) $\lambda_{2}^{e} / \lambda_{2}^{f}$ & 0.52 & 0.45 & 0.47 & 0.52 & 0.66 & 0.61 & 0.78 \\
(2) $\lambda_{2}^{e} / \lambda_{1}$ by Eq. (18) & 0.21 & 0.20 & 0.25 & 0.31 & 0.26 & 0.30 & 0.34 \\
(2) $\div$ (1) $\sim \lambda_{2}^{j} / \lambda_{1}$ & 0.40 & 0.44 & 0.53 & 0.60 & 0.39 & 0.49 & 0.44 \\
\hline
\end{tabular}

Eq. (18) $\lambda_{2}^{e} / \lambda_{1}=1.6\left[\left(\Delta T_{0}\right)^{1 / 4} /\left(\Delta T_{m}\right)^{1 / 2}\right](D \Gamma / k)^{1 / 12} R^{-1 / 12} G^{1 / 6}$

[for steel a] $\lambda_{2}^{e} / \lambda_{1}=0.079 R^{-0.0833} G^{0.167}\left[R: \mathrm{cm} / \mathrm{s}, G:{ }^{\circ} \mathrm{C} / \mathrm{cm}\right]$

[for steel b] $\lambda_{2}^{e} / \lambda_{1}=0.082 R^{-0.0833} G^{0.167}\left[R: \mathrm{cm} / \mathrm{s}, G:{ }^{\circ} \mathrm{C} / \mathrm{cm}\right]$ 
is supported by the semi-theoretical considerations.

\section{Discussion}

In introducing Eq. (13) in Kurz's theory, shape of the primary dendrite is postulated as axial-symetric ellipsoid, which leads to the $R$-exponent: $m=-0.25$. There is another theoretical explanation ${ }^{17)}$ giving the same figure for $R$-exponent, and some experiments, e.g., a very careful work done by $\mathrm{McCartney} \mathrm{et} \mathrm{al.}{ }^{18)}$ using $\mathrm{Al}-\mathrm{Mg}-\mathrm{Si}$ alloys, support these theoretical results.

Nevertheless, many experimental works using a variety of materials ranging from metallic alloys ${ }^{11-13,19-21)}$ and transparent organic compounds ${ }^{22)}$ do not converge into the theoretical figure: $m=-0.25$. Furthermore, Mason et al. ${ }^{20)}$ proved that neither $R$-exponent: $m$ nor $G$-exponent: $n$ is constant for steady dendritic solidification, analysing their own work and those of Klaren et $a l .{ }^{19)}$ and Spittle et al. ${ }^{21)}$ any of which is done with also very careful experiments using $\mathrm{Pb}-\mathrm{Sn}$ alloys. Mason et $a l .{ }^{20)}$ even suggested that the relationship: $\lambda_{1}=$ (const.) $R^{m} G^{n}$ is 'merely a convenient form for representing experimental data taken over a limited range of experimental variables'. Indeed, another observation done by Somboonsuk et al. $^{22)}$ with succinonitrile- $5.5 \mathrm{~mol} \%$ acetone system, in which the present author see the primary significance to verification of the premises for the above theories, gives quite different $m$-value, notwithstanding the tip morphology of the primary dendrite coincides quantitatively with the theories which sustained the above mentioned theoretical treatments of primary dendrite arm spacing.

As far as C-Mn steel is concerned, only a few works have been opened. And there seems to be no adequate background concluding what is the relieable $m$-, $n$-value. Therefore, it is the best numerical treatment to take a regression adopting $n=-0.5$, which many experimental works as well as the theories converge into. Eq. (1) in the present work unexpectedly coincides with theories in this respect, although the regression ${ }^{1)}$ did not suppose any $a$ pri-o-ri $n$-value, and it should be reminded the experimental regression, i.e., Eq. (1) gives nearly the same $\lambda_{1}$-value which is calculated with the theoretical Eq. (13) as shown in Table 2. This assures the present discussion about $\lambda_{2}^{f}$ vs $\lambda_{1}$ relationship based on Eq. (13) does not lead to wrong result practically, although it might not be selfconsistent logically

The starting point of secondary arm roughening is arbitrarily designated as the point withdrawn in the axial direction by $(1 / 8) r$ from the primary tip as shown in Fig. 1. It is based on the following approximation. If the first one wavelength of perturbation along the curvature: $\lambda_{S}^{(1)}$ is equal to the radius of curvature: $r$, it is calculated mathematically that the first secondary arm spacing: $\lambda_{2}^{(1)}$ is slightly smaller than one tenth of $r$ in axial direction, or $\lambda_{2}^{(1)} \sim 0.1 r$, which is again adjusted to the easiness of numerical treatment; $\sim 2^{-3} r$. This introduces Eq. (15), and Eq. (17). Applying Eq. (17) to steel a and steel b, the numerical formulae,

$$
\text { for steel a: } \begin{aligned}
& \lambda_{2}^{e}[\mu \mathrm{m}]=63.3(R G)^{-1 / 3} \\
& {\left[R: \mathrm{cm} / \mathrm{s}, G:{ }^{\circ} \mathrm{C} / \mathrm{cm}\right] }
\end{aligned}
$$

for steel $\mathrm{b}: \quad \lambda_{2}^{e}[\mu \mathrm{m}]=63.6(R G)^{-1 / 3}$

$\left[R: \mathrm{cm} / \mathrm{s}, G:{ }^{\circ} \mathrm{C} / \mathrm{cm}\right]$

are obtained. The calculated $\lambda_{2}^{e} s$ coincide with the experimental $\lambda_{2}\left(T_{S}\right)$ as shown in Table 3 .

\section{Conclusion}

The primary dendrite arm spacing: $\lambda_{1}$ of C-Mn steel solidified uni-directionally in steady state is well described by Kurz's theoretical analysis which is based on thermodynamic perturbation theory, or marginal stability criterion. Their approximation with axial symmetric ellipsoid morphology for dendrite shape gives a fairly good evaluation for the dependency of $\lambda_{1}$-value upon primary tip velocity, however experimental results indicating some deviations from the theoretical value should be also acceptable.

Growth or roughening behavior of secondary arm spacing: $\lambda_{2}$ is also numerically described, depending on a model proposed by the present work. It is composed of two mechanisms, one is thermodynamic perturbation around primary dendrite tip, and the other is Ostwald ripening or sintering/coalescence, both of which require time dependency of roughening kinetic as time-exponent with $0.25-0.4$. The present author regarded the exponent simply as $1 / 3$, and obtained an equation with which the ratio $\lambda_{2}^{f} / \lambda_{1}$ is estimated to be nearly one half, with aid of a complementary experimental result of $\lambda_{2}^{f}$-relation to the calculated $\lambda_{2}^{e}$.

\section{Acknowledgment}

The author expresses sincere gratitude to Prof. Dr. Takateru Umeda and Prof. Dr. Toshio Suzuki of The University of Tokyo for the instruction and discusson on the experiments and theories in the latest years.

\section{Nomenclature}

$\lambda_{1}$ : Primary dendrite arm spacing

$\lambda_{2}$ : Secondary dendrite arm spacing

$\lambda_{2}^{f}$ : Secondary dendrite arm spacing when overall system completes solidification

$\lambda_{2}^{e}$ : Secondary dendrite arm spacing at the location where temperature is $T_{S}$

$R$ : Growth rate of primary dendrite tip

$G$ : Temperature gradient ahead of primary dendrite tip, or approximately along solid/ liquid zone

$C$ : Concentration of solute (=carbon, in the present report)

$D$ : Diffusion coefficient of carbon in melt steel ahead of dendrite tip

$D_{t h}, D_{t h}^{\prime}:$ Thermal diffusivity in steel melt, and that in dendrite body around primary dendrite tip

$T$ : Temperature at arbitrary point in steel melt around primary dendrite tip

$T^{\prime}$ : Temperature at arbitrary point in dendrite body

$\omega$ : Frequency of thermodynamic perturbation along radial co-ordinate of primary dendrite axis, or along parabolic co-ordinate on primary dendrite tip 
$\sigma:$ Free energy of solid/liquid interface per unit volume

A: Latent heat of steel melt per unit volume

$K_{S}, K_{L}$ : Average curvature at a point on solid-side, and that on liquid-side of interface

$T_{E}:$ Equilibrium melting temperature

$\Gamma^{\prime}, \Gamma: \quad \Gamma^{\prime}=\sigma / \Lambda$, typically given as $\sim 10^{-8} \mathrm{~cm}$ according to Mullins et al. ${ }^{16)} \Gamma=T_{E} \Gamma^{\prime}=\sigma T_{E} / \Lambda$ is called as Gibbs-Thompson-parameter, given in the present discusson as $\sim 10^{-5}{ }^{\circ} \mathrm{Ccm}$

$\omega^{*}: \quad(R / 2 D)+\left\{(R / 2 D)^{2}+\omega^{2}\right\}^{1 / 2}$

$k$ : Partition coefficient of solute $(=$ carbon $)$, $p=1-k$

$M$ : Slope of liquidus line in equilibrium phase diagram; ${ }^{\circ} \mathrm{C} /$ unit-concentration

$g, g^{\prime}: \quad g=2 \kappa_{L} G_{L} /\left(\kappa_{L}+\kappa_{S}\right), \quad g^{\prime}=2 \kappa_{S} G_{S} /\left(\kappa_{L}+\kappa_{S}\right)$, where $\kappa$ and $G$ mean thermal conductivity and temperature gradient with suffix $L$ for liquid-side and $S$ for solid-side of the unperturbed interface

$G_{C}$ : Concentration gradient in the liquid at unperturbed interface

$\delta$ : Amplitude of perturbation

$d_{0}$ : Perturbed capillarity length at primary dendrite tip

$r$ : Radius of curvature at primary dendrite tip

$\lambda_{S}$ : Wave length of perturbation along unperturbed dendrite surface

$\Delta T_{0}, \Delta T_{m}: \Delta T_{0}=T_{L}-T_{S}, \Delta T_{m}=T_{L}-T_{e}$, where $T_{L}:$ liquidus, $T_{S}$ : solidus and $T_{e}$ : eutectic solidification temperature in residual melt

\section{REFERENCES}

1) M. Imagumbai: ISIJ Int., 34 (1994), 896.

2) W. Kurz and D. J. Fisher: Acta Metall., 29 (1981), 11.

3) D. J. Fisher and W. Kurz: Acta Metall., 28 (1980), 777

4) W. W. Mullins and R. F. Sekerka: J. Appl. Phys., 35(1964), 444.

5) J. S. Langer and H. Müller-Krumbhaar: J. Cryst. Growth, 42 (1977), 11.

6) J. S. Langer and H. Müller-Krumbhaar: Acta Metall., 26 (1978), 1681.

7) J. S. Langer and H. Müller-Krumbhaar: Acta Metall, 26 (1978), 1689.

8) H. Müller-Krumbhaar and J. S. Langer: Acta Metall., 26 (1978), 1697.

9) M. E. Glicksman and P. W. Voorhees: Metall.Trans., 15A (1984), 995.

10) T. Z. Kattamis, J. C. Coughlin and M. C. Flemings: Trans. TMS AIME, 239 (1967), 1504.

11) H. Jacobi and K. Schwerdtfeger: Metall. Trans., 7A (1976), 811.

12) M. A. Taha, H. Jacobi, M. Imagumbai and K. Schwerdtfeger: Metall. Trans., 13A (1982), 2131.

13) K. P. Young and D. H. Kirkwood: Metall. Trans., 6A (1975), 197.

14) P. C. Dann, J. A. Eady and L. M. Hogan: J. Aust. Inst. Metals, 19 (1974), 140

15) J. F. Elliott, M. Gleiser and V. Ramakrishna: Thermochemistry For Steelmaking, Pergamon Press, New York, (1963), 702.

16) W. W. Mullins and R. F. Sekerka: J. Appl. Phys., 34 (1963), 323.

17) J. D. Hunt: Solidification and Castings of Metals, The Metals Society, London, Book192, (1972), 3.

18) D. G. McCartney and J. D. Hunt: Acta Metall., 29(1981), 1851.

19) C. M. Klaren, J. D. Verhoeven and R. Trivedi: Metall. Trans., 11A (1980), 1853.

20) J. T. Mason, J. D. Verhoeven and R. Trivedi: J. Cryst. Growth, 59 (1982), 516.

21) J. A. Spittle and D. M. Lloyd: Solidification and Casting of Metal, The Metal Society, Book 192, London, (1979), 15.

22) K. Somboonsuk, J. T. Mason and R. Trivedi: Metall. Trans., 15A (1984), 967. 